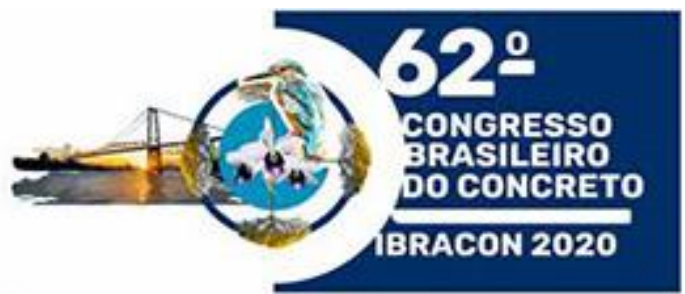

1 a 4 de setembro de 2020 / Florianopolis - SC USO E OPERACTAO DE ESTRUTURAS DE CONCRETO
Anais do

$62^{\circ}$ Congresso Brasileiro do Concreto

CBC2020

Setembro / 2020
O

IBRACON

(C) 2020 - IBRACON - ISSN 2175-8182

\title{
Avaliação de desempenho técnico e ambiental de cimentos compostos por elevados teores de adições minerais
}

\author{
Technical and environmental performance assessment of blended cements with high \\ content of supplementary cementitious materials
}

\author{
MENDES, A. A. F. (1); RODRIGUES, A. L. M. V. (1); BATTAGIN, A. F. (2); GOMES, V. \\ (3); SILVA, M. G. (4).
}

(1) Mestrando(a) do Programa de Pós-Graduação em Engenharia Civil, Universidade Federal do Espírito Santo, Vitória - ES.

(2) Gerente de Tecnologia, Associação Brasileira de Cimento Portland, São Paulo - SP.

(3) Professora Associada da Faculdade de Engenharia Civil e Arquitetura e Urbanismo, Universidade Estadual de Campinas, Campinas - SP.

(4) Professora Titular, Departamento de Engenharia Civil, Programa de Pós-Graduação em Engenharia Civil, Universidade Federal do Espírito Santo,Vitória-ES, e-mail margomes.silva@gmail.com (autora de

\section{Resumo} correspondência).

Os desafios de produção de cimento em um cenário de necessidade de redução de impactos ambientais convergem para a normalização e produção de cimentos compostos, com baixo fator de clínquer e elevados teores de adições minerais. Neste artigo, foram estudados seis cimentos compostos com fator de clínquer variando de $45 \%$ a $50 \%$, constituídos por pelo menos dois tipos diferentes de adições minerais. Os cimentos compostos foram estudados quanto ao desempenho técnico, por meio do atendimento aos requisitos e critérios da ABNT NBR 16697:2018, e ambiental, por meio da avaliação de ciclo de vida, estimando as emissões de gases de efeito estufa (GEE) e verificando o atendimento das recomendações para redução de emissão de $\mathrm{CO}_{2}$ extraídas do Cement Technology Roadmap Brazil 2050. Os resultados obtidos mostraram o potencial desses cimentos atenderem às diretrizes de redução das emissões de GEE. Ao se elevar, porém, o teor de fíler calcário para $25 \%$, deve-se atentar para as exigências normalizadas relacionadas com a perda ao fogo e com a resistência mecânica. Dentre as alternativas investigadas, destaca-se o cimento constituído por argila calcinada, escória de alto-forno e fíler calcário, com fator de clínquer de $45 \%$, que apresentou resistência à compressão próxima a $23 \mathrm{MPa}$, aos 3 dias de idade, e $41 \mathrm{MPa}$, aos 28 dias de idade, comprovando que a sinergia entre as adições minerais, explorada nesse cimento, justifica ações de pesquisa e desenvolvimento na indústria de cimento.

Palavra-Chave: Cimentos compostos; adições minerais; desempenho; emissões de gases de efeito estufa.

\section{Abstract}

The challenges of cement production in a scenario with pressing need to reduce environmental impacts converge towards standardization and production of blended cements with low clinker and high supplementary cementitious materials contents. In this paper, we studied six blended cements, with clinker content ranging from $45 \%$ to $50 \%$ and composed by at least two supplementary cementitious materials. The cements were studied in terms of technical performance, through compliance with ABNT NBR 16697:2018; environmental performance was assessed by comparing greenhouse gas (GHG) emissions estimates by life cycle assessment with the recommendations outlined in the Cement Technology Roadmap Brazil 2050. The results showed the potential of those cements to meet the Roadmap recommendations regarding GHG emissions. However, the increase in limestone content raises alert flags regarding compliance with standardized loss of ignition and compressive strength. The 45\%-clinker quaternary blend with calcined clay, granulated blast furnace slag and limestone stood out (compressive strength close to $23 \mathrm{MPa}$, at 3 days, and to $41 \mathrm{MPa}$, at 28 days) and confirmed that the synergy effect among supplementary cementitious materials justifies research and development actions within the cement industry.

Keywords: Blended cements; supplementary cementitious materials; performance; greenhouse gas emissions. 


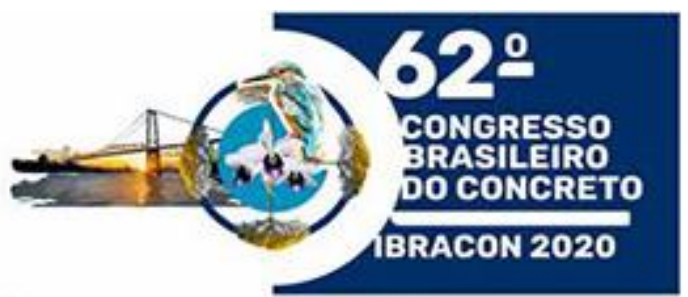

USO E OPERACAAO DEESTRUTURAS DE CONCRETO
Anais do

$62^{\circ}$ Congresso Brasileiro do Concreto

CBC2020

Setembro / 2020

(@) 2020 - IBRACON - ISSN 2175-8182

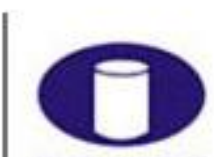

IBRACON

\section{Introdução}

Materiais à base de cimento, como concretos e argamassas, são largamente utilizados em diversas obras de engenharia, pela combinação de facilidade construtiva e baixo custo. Apesar da sua importância nos contextos sociais e econômicos, a produção do cimento Portland é também uma atividade que resulta em impactos ambientais significativos, pois, além da exploração de jazidas naturais, é responsável por cerca de $7 \%$ da emissão total de $\mathrm{CO}_{2}$ (SNIC, 2019).

Para colaborar na redução desses impactos ambientais, foram desenvolvidos roteiros específicos para a indústria cimentícia, propondo trajetórias e recomendações para uma menor emissão de $\mathrm{CO}_{2}$. No cenário mundial, foi publicado, em 2018, o Technology Roadmap: Low-Carbon Transition in the Cement Industry, elaborado pela International Energy Agency (IEA), pelo The Cement Sustainability Initiative (CSI) e pelo World Business Council for Sustainable Development (WBCSD). Em 2019, foi publicado o Cement Technology Roadmap - Potential for reduction of carbon emissions for the Brazilian Cement Industry by 2050, desenvolvido pela Associação Brasileira de Cimento Portland (ABCP) e pelo Sindicato Nacional da Indústria de Cimento (SNIC) especificamente para o cenário brasileiro.

Dentre as estratégias propostas nos dois roteiros, o uso de adições minerais como substituto do clínquer desponta como a de maior potencial para redução das emissões de $\mathrm{CO}_{2}$. O Cement Technology Roadmap Brazil 2050 (SNIC, 2019) estima que o uso de adições minerais como substituto do clínquer pode contribuir para redução de $69 \%$ da emissão acumulada de $\mathrm{CO}_{2}$ entre 2014 e 2050, com base no crescimento do teor médio de adição mineral no cimento brasileiro de 35\%, em 2020, para 48\%, em 2050.

Além de todas as preocupações ambientais associadas com a produção do cimento, suas características e propriedades físicas, químicas e mecânicas devem ser compatíveis com a utilização na construção civil, normalizadas, no Brasil, pela ABNT NBR 16697:2018. Assim, formulações de cimentos mais sustentáveis e que atendam a requisitos técnicos tornaram-se um desafio para a indústria de cimento e para os pesquisadores.

Cimentos compostos, especialmente aqueles formados pela combinação de duas ou mais adições minerais, despontam como uma alternativa para permitir elevados teores de substituição de clínquer (SKIBSTED, SNELLINGS, 2019). Além disso, o uso de cimentos ternários e quaternários tendem a apresentar melhora no desempenho técnico quando comparado a cimentos binários, devido ao efeito sinergético entre as adições minerais (FERNÁNDEZ, GARCÍA CALVO; ALONSO, 2018). Nesse tipo de cimento, além da reação principal, seja ela pozolânica ou de hidratação, a interação entre as adições minerais pode resultar em diferentes reações secundárias (KRISHNAN; EMMANUEL; BISHNOI, 2019). Puerta-Falla et al. (2015) citam que o carbonato de cálcio presente no fíler calcário reage com a alumina fornecida por adições minerais ricas em alumina - como a argila calcinada, escória de alto-forno e cinza volante - resultando na formação de carboaluminato e contribuindo para a resistência mecânica.

Este artigo estuda o desempenho técnico e ambiental de seis cimentos compostos - quatro cimentos ternários e dois cimentos quaternários - considerando as adições minerais com potencial para uso comercial e sua disponibilidade regional, quais sejam: escória granulada de alto-forno, cinza volante, argila calcinada e fíler calcário. O fíler calcário e a argila calcinada apresentam disponibilidade quase ilimitada, sendo de fácil acesso nas indústrias ANAIS DO 62ํㅡㄴ CONGRESSO BRASILEIRO DO CONCRETO - CBC2020 - 62CBC2020 


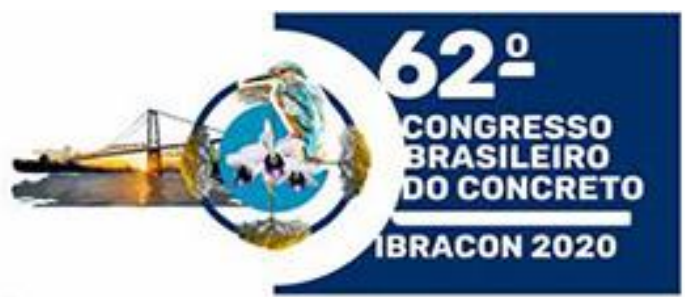

Anais do

$62^{\circ}$ Congresso Brasileiro do Concreto CBC2020

Setembro / 2020

(C) 2020 - IBRACON - ISSN 2175-8182

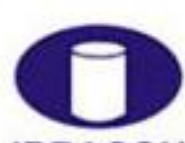

IBRACON

cimenteiras. Já a disponibilidade de escória de alto-forno e cinza volante, é regionalizada e concentra-se, respectivamente, nas regiões sudeste e sul do país. Seguindo a trajetória de aumento do teor de fíler calcário prevista no Cement Technology Roadmap Brazil 2050 (SNIC, 2019), para os cimentos ternários, foram estudadas duas formulações com escória de alto-forno e fíler calcário; e duas com cinza volante e fíler calcário. Já os cimentos quaternários eram compostos por combinações de escória de alto-forno, argila calcinada e fíler calcário, e de cinza volante, argila calcinada e fíler calcário.

A avaliação do desempenho ambiental contrastou as emissões estimadas de gases de efeito estufa (em $\mathrm{CO}_{2 e q}$ ), obtidas por avaliação de ciclo de vida, com as recomendações para redução de emissão de GEE (em $\mathrm{CO}_{2 e q}$ ) para a indústria nacional de cimento traçadas a partir do Cement Technology Roadmap Brazil 2050 (SNIC, 2019). A avaliação do desempenho técnico foi fundamentada no atendimento dos requisitos e critérios especificados na ABNT NBR 16697:2018.

\section{Abordagem metodológica}

A Figura 1 mostra as etapas experimentais adotadas neste estudo.

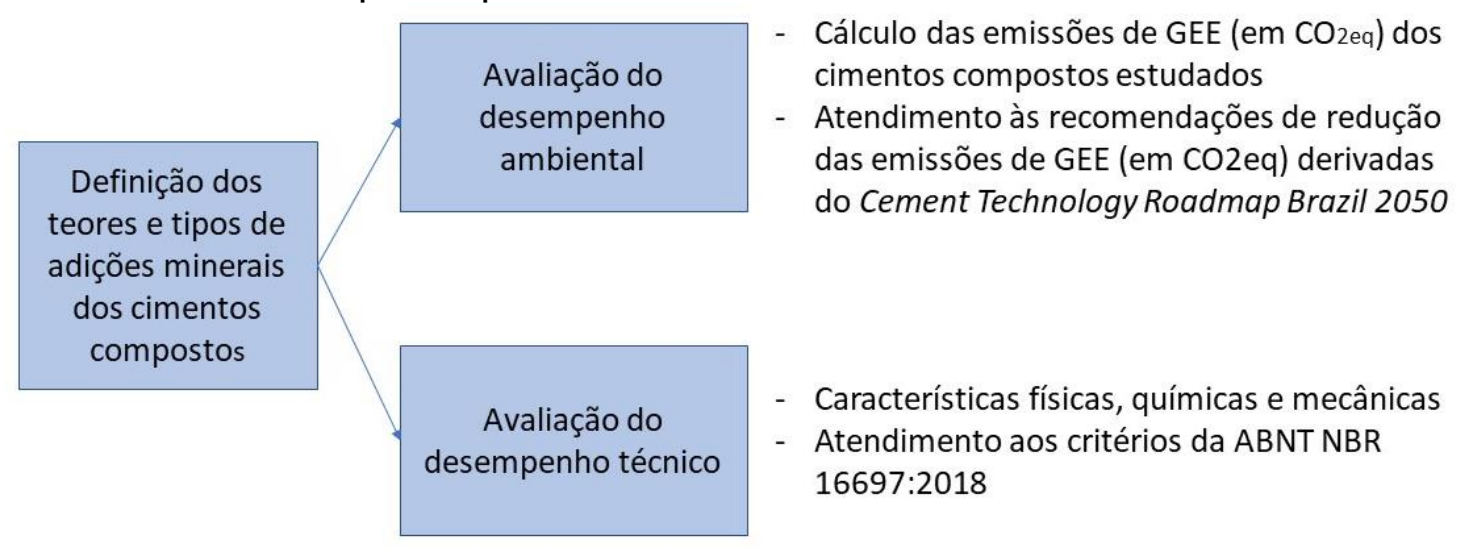

Figura 1 - Fluxograma das etapas do projeto experimental (Fonte: os autores)

\subsection{Materiais}

Os materiais utilizados nessa pesquisa são: cimento Portland de alta resistência inicial (CP V ARI), escória granulada de alto-forno, argila calcinada, cinza volante e fíler calcário. O CP V ARI, a escória de alto-forno e o fíler calcário foram utilizados na finura Blaine recebida da indústria cimenteira: $491,23 \mathrm{~m}^{2} / \mathrm{kg}, 417,96 \mathrm{~m}^{2} / \mathrm{kg}$ e $380,72 \mathrm{~m}^{2} / \mathrm{kg}$, respectivamente. A argila calcinada e a cinza volante passaram pela moagem em laboratório por um período de $5 \mathrm{~h}$ em um moinho de bolas, mais 4 min em um moinho de argolas.

A distribuição granulométrica dos materiais foi determinada utilizando um granulômetro a laser (CILAS - Compagnie Industrielle des Lasers - modelo 1090 LD) por via úmida, com isopropanol como meio dispersante (Figura 2). A cinza volante apresentou os menores diâmetros, enquanto a argila calcinada exibiu os maiores. 


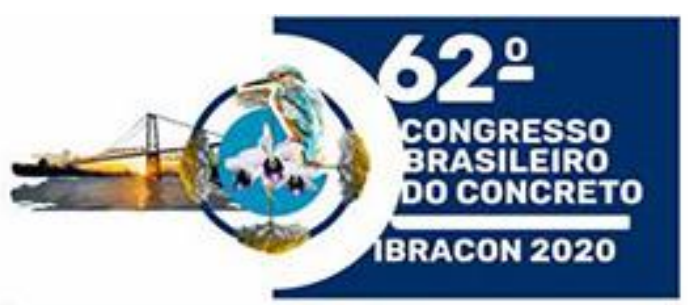

Anais do

$62^{\circ}$ Congresso Brasileiro do Concreto $\mathrm{CBC} 2020$

Setembro / 2020

IBRACON

(C) 2020 - IBRACON - ISSN 2175-8182

USO E OPERACTAO DE ESTRUTURAS DE CONCRETO

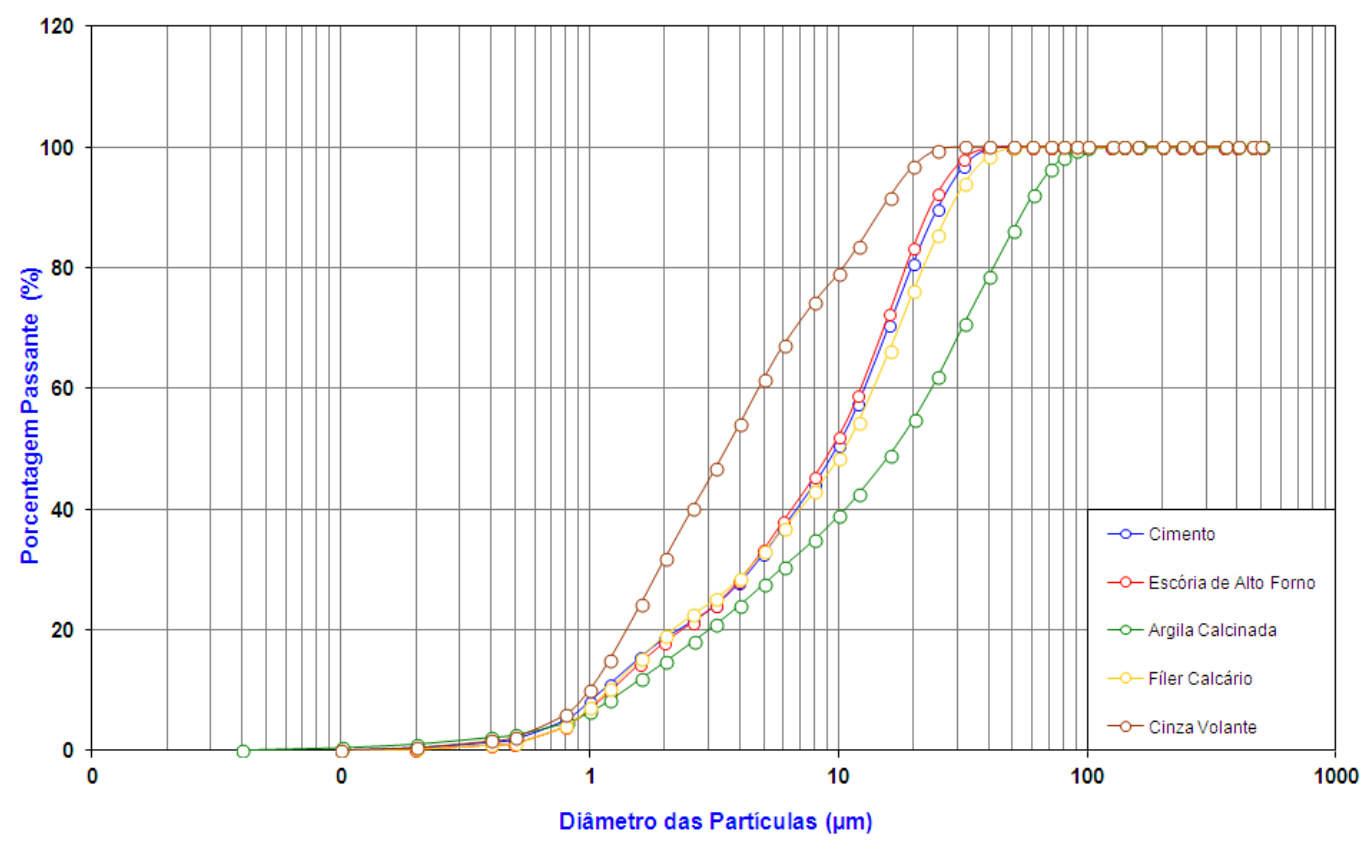

Figura 2 - Distribuição granulométrica dos materiais utilizados (Fonte: os autores)

A composição química dos materiais (Tabela 1) foi realizada por fluorescência de raios $X$ (FRX), utilizando amostras em pérolas para a argila calcinada e cinza volante (equipamento: MagiX PRO - Philips com o software SuperQ), e amostras em pastilhas prensadas para o CP V ARI, escória de alto-forno e fíler calcário (equipamento: NexGo Rigaku).

Tabela 1 - Composição química dos materiais utilizados (Fonte: os autores)

\begin{tabular}{|c|c|c|c|c|c|}
\hline Óxidos & CP V-ARI & Argila calcinada & Cinza volante & $\begin{array}{c}\text { Escória de } \\
\text { alto-forno }\end{array}$ & $\begin{array}{c}\text { Fíler } \\
\text { calcário }\end{array}$ \\
\hline $\mathrm{SiO}_{2}(\%)$ & 17,7 & 68,11 & 61,75 & 35,8 & 1,50 \\
\hline $\mathrm{Al}_{2} \mathrm{O}_{3}(\%)$ & 4,25 & 19,66 & 21,78 & 13,6 & 0,33 \\
\hline $\mathrm{Fe}_{2} \mathrm{O}_{3}(\%)$ & 3,08 & 5,66 & 5,32 & 0,08 & - \\
\hline $\mathrm{CaO}(\%)$ & 57,43 & 0,10 & 1,81 & 41,1 & 47,50 \\
\hline $\mathrm{MgO}(\%)$ & 2,16 & 0,05 & 0,84 & 4,77 & 5,92 \\
\hline $\mathrm{Na}_{2} \mathrm{O}(\%)$ & 0,16 & - & 0,71 & - & - \\
\hline $\mathrm{K}_{2} \mathrm{O}(\%)$ & 0,32 & 0,29 & 3,01 & 0,22 & 0,08 \\
\hline $\mathrm{TiO}_{2}(\%)$ & - & 1,83 & 0,94 & 0,44 & - \\
\hline $\mathrm{P}_{2} \mathrm{O}_{5}(\%)$ & - & 0,051 & 0,079 & - & - \\
\hline $\mathrm{MnO}_{(\%)}$ & - & 0,01 & 0,03 & - & - \\
\hline $\mathrm{SO}(\%)$ & 3,93 & 0,01 & 0,11 & 3,2 & 0,04 \\
\hline $\mathrm{PF}_{3}(\%)$ & 3,70 & 4,02 & 3,26 & - & 42,35 \\
\hline $\mathrm{Soma}$ & 92,73 & 99,79 & 99,64 & 99,21 & 97,72 \\
\hline
\end{tabular}

Por serem adições minerais pozolânicas, foram realizados ensaios de Chapelle Modificado, conforme a ABNT NBR 15895:2010, para a argila calcinada $(601,54 \mathrm{mg} \mathrm{Ca}(\mathrm{OH}) 2 / \mathrm{g})$ e para a cinza volante $\left(708,36 \mathrm{mg} \mathrm{Ca}(\mathrm{OH})_{2} / \mathrm{g}\right)$. Tais valores confirmam a reatividade dessas adições minerais, superiores ao valor mínimo $\left(436 \mathrm{mg} \mathrm{Ca}(\mathrm{OH})_{2} / \mathrm{g}\right)$ para uma adição mineral ser considerada pozolânica (Raverdy et al., 1980). 


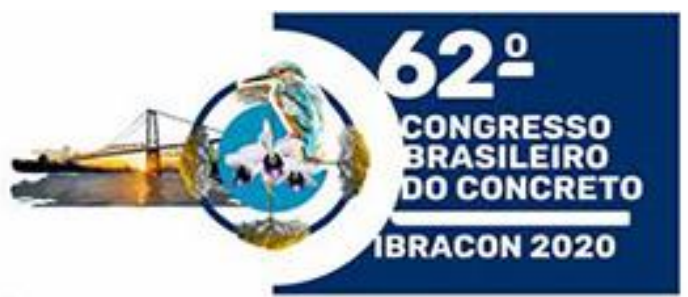

USO E OPERACTAO DE ESTRUTURAS DE CONCRETO
Anais do

$62^{\circ}$ Congresso Brasileiro do Concreto $\mathrm{CBC} 2020$

Setembro / 2020

(C) 2020 - IBRACON - ISSN 2175-8182

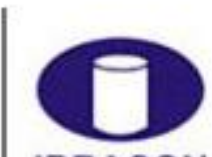

IBRACON

Para a escória de alto-forno, foram determinados o grau de vitrificação (98\%) e o índice de refração $(1,65)$. Essas características, juntamente com sua basicidade, conferem à escória solubilidade para a desenvolvimento de sua atividade hidráulica (SILVA; BATTAGIN; GOMES, 2017).

\subsection{Definição dos teores e tipos de adições minerais dos cimentos compostos}

A Tabela 2 mostra a composição, em massa, dos seis cimentos estudados. Para a nomenclatura, as letras representam cada adição mineral com sua inicial do nome em inglês ("B" para blast furnace slag, "F" para fly ash, "C" para calcined clay e para "L" para limestone), seguida da sua porcentagem na composição do cimento. O percentual de gipsita é fixo em $5 \%$ e o percentual de clínquer é o complemento para totalizar $100 \%$.

Tabela 2 - Teores dos constituintes dos cimentos compostos estudados (Fonte: os autores)

\begin{tabular}{|c|c|c|c|c|c|c|}
\hline Cimento Composto & Clínquer & Gipsita & $\begin{array}{c}\text { Escória de } \\
\text { alto-forno }\end{array}$ & $\begin{array}{c}\text { Cinzas } \\
\text { volantes }\end{array}$ & $\begin{array}{c}\text { Argila } \\
\text { Calcinada }\end{array}$ & $\begin{array}{c}\text { Fíler } \\
\text { Calcário }\end{array}$ \\
\hline C1 - B25/L20 & $50 \%$ & $5 \%$ & $25 \%$ & - & - & $20 \%$ \\
\hline C2 - F25/L20 & $50 \%$ & $5 \%$ & - & $25 \%$ & - & $20 \%$ \\
\hline C3 - B20/L25 & $50 \%$ & $5 \%$ & $20 \%$ & - & - & $25 \%$ \\
\hline C4 - F20/L25 & $50 \%$ & $5 \%$ & - & $20 \%$ & - & $25 \%$ \\
\hline C5 - B10/C25/L15 & $45 \%$ & $5 \%$ & $10 \%$ & - & $25 \%$ & $15 \%$ \\
\hline C6 - F10/C25/L15 & $45 \%$ & $5 \%$ & - & $10 \%$ & $25 \%$ & $15 \%$ \\
\hline
\end{tabular}

Os cimentos compostos foram definidos a partir da revisão de literatura, seguindo algumas tendências previstas no Cement Technology Roadmap Brazil 2050 (SNIC, 2019) e no projeto da norma europeia prEN197-1:2019. Da revisão de literatura, observou-se que, ao utilizar adições combinadas, o fator de clínquer próximo de $50 \%$ permite que se alcancem propriedades mecânicas e alguns aspectos relacionados com a durabilidade semelhantes aos cimentos sem adições minerais (BOHÁC et al., 2014; SCRIVENER et al., 2018b). Além disso, o Cement Technology Roadmap Brazil 2050 (SNIC, 2019) prevê um fator de clínquer médio dos cimentos brasileiros de 52\% em 2050; e um aumento do teor de fíler calcário na composição média dos cimentos, partindo de 13\%, em 2020, para 25\%, em 2050. Assim, os cimentos aqui estudados apresentam teores de fíler calcário entre $15 \%$ e $25 \%$.

Os cimentos C1 - B25/L20 e C3 - B20/L25 são constituídos por escória de alto-forno, fíler calcário e clínquer, assim como os cimentos estudados por Adu-Amankwah et al. (2017), Gao et al. (2016) e Arora et al. (2016). A composição do cimento C1 - B25/L20 está prevista no projeto da norma europeia prEN197-1:2019, com porcentagens de adições minerais dentro dos limites previstos para o cimento CEM II/C-M (S-L), que permite o uso em conjunto de clínquer (de 50 a 64\%), escória de alto-forno (de 16 a 44\%) e fíler calcário (de 6 a 20\%). O cimento C3 - B20/L25 prevê o aumento do teor de fíler calcário para 25\%, com redução do teor de escória de alto-forno.

O cimento C2 - F25/L20 e o C4 - F20/L25 são constituídos por cinza volante, fíler calcário e clínquer, assim como os cimentos estudados por Wang (2018), Vance et al. (2013) e De Weerdt et al. (2011). A composição do cimento C2 - F25/L20 está prevista no projeto da norma europeia prEN197-1:2019, estando as porcentagens de adições minerais dentro dos limites previstos para o cimento CEM II/C-M (V-L), que permite o uso em conjunto de clínquer (de 50 a 64\%), cinza volante (de 16 a 44\%) e fíler calcário (de 6 a 20\%). 


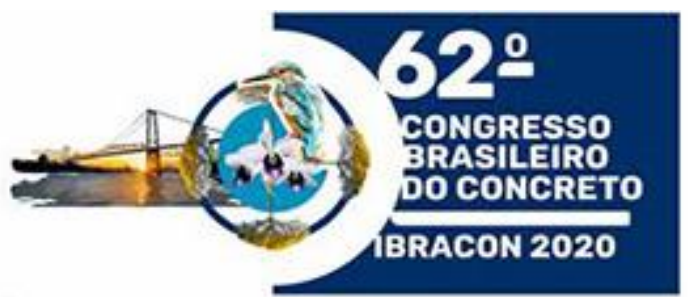

USO E OPERACAO DE ESTRUTURAS DE CONGRETO
Anais do

$62^{\circ}$ Congresso Brasileiro do Concreto $\mathrm{CBC} 2020$

Setembro / 2020

(C) 2020 - IBRACON - ISSN 2175-8182

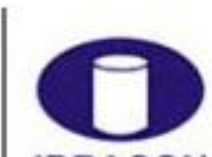

IBRACON

O cimento C4 - F20/L25 prevê o aumento do teor de fíler calcário para $25 \%$, com a redução do teor de cinza volante. Finalmente, os cimentos C5 - B10/C25/L15 e C6 - F10/C25/L15 visam avaliar o efeito da redução do fator de clínquer pela introdução de mais uma adição mineral. Nesses dois cimentos, foi adicionada argila calcinada, uma adição mineral com ampla disponibilidade e presente em quase toda fábrica, uma vez que é a mesma argila que se utiliza na fabricação do clínquer. Scrivener et al. (2018) observaram que a interação entre argila calcinada e fíler calcário apresenta potencial emprego na produção de cimentos. Assim, reduziu-se o clínquer e a argila calcinada em 5\%, e adicionou-se $10 \%$ de escória de alto-forno (C5 - B10/C25/L15) ou de cinza volante (C6 - F10/C25/L15) para manter proporções próximas às estudadas por Scrivener et al. (2018) e o alinhamento às recomendações de redução de emissão de gases de efeito estufa estabelecidas no Cement Technology Roadmap Brazil 2050 (SNIC, 2019).

\subsection{Avaliação do desempenho ambiental}

\subsubsection{Cálculo das emissões de GEE dos cimentos compostos estudados}

Para o cálculo das emissões de GEE (em $\mathrm{CO}_{2 e q}$ ) dos cimentos estudados, adotou-se a metodologia descrita em Mendes et al. (2019). Os cálculos foram feitos com base em inventários de ciclo de vida do clínquer e de adições minerais (SILVA, BATTAGIN, GOMES, 2017), sendo calculada a emissão de GEE (em $\mathrm{CO}_{2 e q}$ ) para cada tonelada de cimento. $A$ emissão de GEE (em $\mathrm{CO}_{2 e q}$ ) é calculada por:

Tabela 3 - Procedimento para cálculo das emissões de GEE (em $\mathrm{CO}_{2 e q}$ ) para cada cimento estudado (Fonte: MENDES et al. (2019))

\begin{tabular}{|c|l|}
\hline \multirow{2}{*}{\begin{tabular}{l|l|} 
Emissões de $\mathrm{GEE}=\mathrm{Fe}_{\text {clínquer }} * \mathrm{P}_{\text {clínquer }}+$ \\
$\sum \mathrm{Eo}\left(\mathrm{Pc}^{*} \mathrm{Fe}_{\text {const }}\right)$
\end{tabular}} & $\begin{array}{l}\text { Fe que: } \\
\mathrm{P}_{\text {clínquer. }}=\text { Teor de clínquer na composição do cimento } \\
\left.\text { Eo = Emissão de GEE (em } \mathrm{CO}_{2 \mathrm{eq}}\right) \text { de cada constituinte do cimento. } \\
\mathrm{Pc}=\text { Teor de cada constituinte }\end{array}$ \\
\hline
\end{tabular}

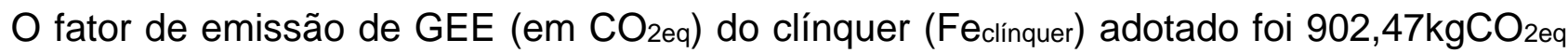
por tonelada produzida, extraído de datasets brasileiros fornecidos para a Ecoinvent, maior base de dados de inventário de ciclo de vida disponível. O $\mathrm{CO}_{2 e q}$ é um indicador internacionalmente utilizado para comparar as emissões de vários gases de efeito estufa com base na quantidade de dióxido de carbono que teria o mesmo potencial de aquecimento global, medido em um determinado período, geralmente 100 anos (IPCC, 2013). Este indicador é também recomendado pelo IEA EBC Annex 57: Evaluation of Embodied Energy and $\mathrm{CO}_{2}$ Equivalent Emissions for Building Construction (IEA, 2016) e adotado pelo IEA EBC Annex 72: Assessing Life Cycle Related Environmental Impacts Caused by Buildings (IEA, 2018) na quantificação de impactos ambientais no ciclo de vida de materiais de construção e de edificações.

As emissões líquidas de GEE (em $\mathrm{CO}_{2 e q}$ ) evitadas referem-se à subtração das emissões de GEE (em $\mathrm{CO}_{2 e q}$ ) geradas na produção ou beneficiamento das adições minerais do total de emissões de GEE (em CO2eq) geradas na produção do clínquer substituído. A Tabela 4 mostra o fator de emissão de $\mathrm{GEE}$ (em $\mathrm{CO}_{2 e q}$ ) e as emissões líquidas de GEE evitadas para cada adição mineral. 


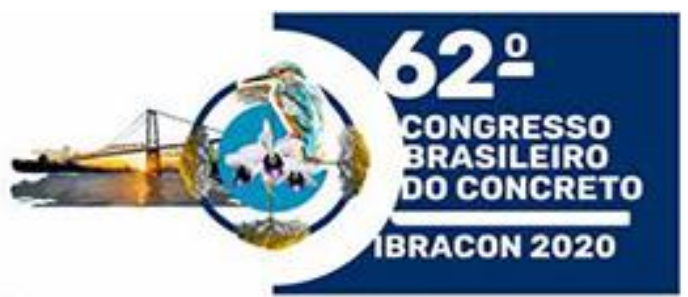

Anais do

$62^{\circ}$ Congresso Brasileiro do Concreto CBC2020

Setembro / 2020

(C) 2020 - IBRACON - ISSN 2175-8182

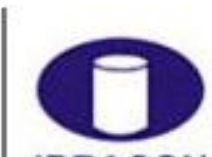

IBRACON

Tabela 4 - Fator de emissão de GEE (em CO2eq) das adições minerais (Fonte: MENDES et al (2019), a partir de dados de SILVA; BATTAGIN; GOMES (2017)).

\begin{tabular}{|c|c|c|c|}
\hline \multirow{2}{*}{$\begin{array}{c}\text { Substituto de } \\
\text { clínquer }\end{array}$} & \multirow{2}{*}{$\begin{array}{c}\text { Fator de Emissão de GEE } \\
\text { (kgCO }_{\text {2eq }} / \text { t de substituto) }^{2}\end{array}$} & \multicolumn{2}{|c|}{$\begin{array}{c}\text { Emissões líquidas de GEE evitadas (SILVA; } \\
\text { BATTAGIN; GOMES, 2017) }\end{array}$} \\
\cline { 3 - 4 } & 3,42 & 899,05 & \% \\
\hline Escória de alto-forno & 22,52 & 879,95 & 99,6 \\
\hline Cinza volante & 14,58 & 887,89 & 97,5 \\
\hline Fíler calcário & 276,27 & 626,2 & 98,4 \\
\hline Argila calcinada & 2,13 & 900,34 & 69,4 \\
\hline Sulfato de cálcio & & & 99,8 \\
\hline
\end{tabular}

2.3.2 Verificação do atendimento às recomendações de redução das emissões de GEE derivadas do Cement Technology Roadmap Brazil 2050

O Cement Technology Roadmap Brazil 2050 (SNIC, 2019) apresenta suas projeções em $\mathrm{CO}_{2}$. No entanto, os dados extraídos de datasets (Tabela 4) estão em $\mathrm{CO}_{2 e q}$, uma vez que consideram, além do $\mathrm{CO}_{2}$, outros gases de efeito estufa. Dessa forma, foi necessário converter as emissões de $\mathrm{CO}_{2}$, previstas no Cement Technology Roadmap Brazil 2050 (SNIC, 2019), para GEE (em CO2eq). Para esse cálculo, determinou-se a emissão de GEE (em $\mathrm{CO}_{2 e q}$ ) da composição média do cimento brasileiro em 2014 (68,9\% de clínquer, $13,60 \%$ de escória de alto-forno, 2,70\% de cinza volante, 7,40\% de fíler calcário, 3,90\% de sulfato de cálcio) e multiplicou-se esse valor pela estimativa de produção de cimento no Brasil de 2014 a 2050 (SNIC, 2019), obtendo, assim, a emissão total de GEE (em CO2eq) de 2014 a 2050, em um cenário que nenhuma alternativa de redução é adotada. Multiplicando a emissão total de GEE (em $\mathrm{CO}_{2 e q}$ ) pelas porcentagens de redução da emissão de $\mathrm{CO}_{2}$ decorrente da contribuição das adições minerais previstas no Cement Technology Roadmap Brazil 2050 (SNIC, 2019), obtém-se a estimativa total das emissões de GEE (em $\mathrm{CO}_{2 e q}$ ), em milhões de toneladas, considerando somente a contribuição das adições minerais de 2024 a 2050 (segunda coluna da Tabela 5). Dividindo esse valor pela estimativa de produção de cimento (terceira coluna da Tabela 5) obtém-se o limite de emissão de GEE (em CO 2 eq) por tonelada de cimento (quarta coluna da Tabela 5). Todo este procedimento está detalhado em Mendes et al. (2019).

Tabela 5 - Estimativa do limite de emissão de GEE (em $\mathrm{CO}_{2 e q}$ ), em milhões de toneladas, projeção da produção de cimento e limite de emissão de GEE (em $\mathrm{CO}_{2 \mathrm{eq}}$ ) por tonelada de cimento (Fonte: os autores, a partir de MENDES et al. (2019) e SNIC (2019))

\begin{tabular}{|c|c|c|c|}
\hline Ano & $\begin{array}{c}\text { Estimativa do limite total de emissão de GEE, } \\
\text { em milhões de toneladas de } \mathrm{CO}_{2 \text { eq, }} \\
\text { considerando a contribuição das adições } \\
\text { minerais (SNIC, 2019) }\end{array}$ & $\begin{array}{c}\text { Projeção da produção } \\
\text { de cimento, em } \\
\text { milhões de toneladas } \\
\text { (SNIC, 2019) }\end{array}$ & $\begin{array}{c}\text { Limite de emissão de GEE, em kg } \\
\mathrm{CO}_{2 \text { eq }} \text { por tonelada de cimento- } \\
\text { considerando somente a } \\
\text { contribuição das adições minerais }\end{array}$ \\
\hline 2020 & 37,88 & 62 & 610,97 \\
\hline 2030 & 47,78 & 87 & 549,20 \\
\hline 2040 & 64,33 & 126 & 510,56 \\
\hline 2050 & 58,57 & 117 & 500,60 \\
\hline
\end{tabular}

O cenário da Tabela 5 que apresenta a menor emissão de GEE (em CO2eq) por tonelada de cimento ocorre em 2050. Assim, para o desempenho ambiental dos cimentos é avaliado 


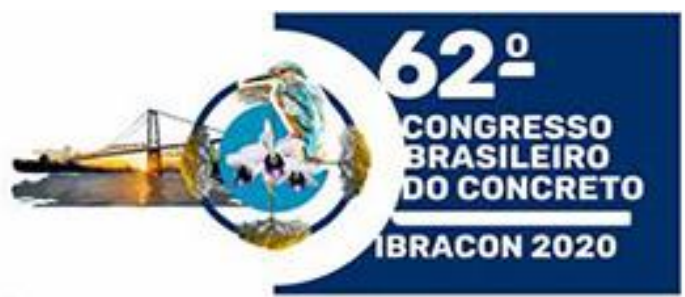

Anais do

$62^{\circ}$ Congresso Brasileiro do Concreto CBC2020

Setembro / 2020

(@) 2020 - IBRACON - ISSN 2175-8182

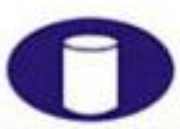

IBRACON

relativamente à recomendação de emissões de GEE derivadas do Cement Technology Roadmap Brazil 2050 para aquele ano ( $\leq 500,60 \mathrm{kgCO} 2 \mathrm{eq} / \mathrm{t})$.

\subsection{Avaliação do desempenho técnico}

A avaliação das propriedades físicas, químicas e mecânicas tem o objetivo de comparar as caraterísticas e propriedades dos cimentos com os requisitos e critérios obrigatórios estabelecidos na ABNT NBR 16697:2018. A Tabela 6 mostra as características e propriedades físicas, químicas e mecânica avaliadas, os métodos de ensaio, os critérios adotados e algumas considerações para a definição dos critérios.

Os critérios para a resistência à compressão, descritos na ABNT NBR 16697:2018, variam conforme a idade, o tipo de cimento e a classe. A Tabela 7 detalha os critérios prescritos pela ABNT NBR 16697:2018 para os cimentos CP III, CP IV e CP II - F, que admitem os teores de escória de alto-forno, cinza volante e fíler calcário presentes nos cimentos estudados.

Tabela 6 - Requisitos, métodos de ensaio e critérios adotados para a avaliação do desempenho técnico dos cimentos estudados (Fonte: os autores, a partir da ABNT NBR 16697:2018 e das normas citadas)

\begin{tabular}{|c|c|c|c|c|c|}
\hline & \multicolumn{2}{|c|}{ Requisito } & $\begin{array}{l}\text { Método de } \\
\text { Ensaio }\end{array}$ & Critério & Considerações \\
\hline \multirow[t]{4}{*}{$\begin{array}{l}\text { Características } \\
\text { químicas }\end{array}$} & \multicolumn{2}{|c|}{ Resíduo Insolúvel (RI) } & $\begin{array}{l}\text { ABNT NBR } \\
\text { NM 15:2012 }\end{array}$ & $\leq 5 \%$ & $\begin{array}{c}\text { Para cimentos com teor de material } \\
\text { pozolânico entre 15\% e 50\%, como o CP } \\
\text { IV, a ABNT NBR 16697:2018 não define } \\
\text { um critério relacionado ao resíduo } \\
\text { insolúvel. Assim, o resíduo insolúvel foi } \\
\text { determinado para todos os cimentos, mas } \\
\text { foi avaliado o atendimento ao critério } \\
\text { somente para os cimentos C1 - B25/L20 e } \\
\text { C3 - B20/L25, considerando o critério para } \\
\text { o CP III, por este ser composto com } \\
\text { escória de alto-forno. }\end{array}$ \\
\hline & \multicolumn{2}{|c|}{ Perda ao fogo (PF) } & $\begin{array}{l}\text { ABNT NBR } \\
\text { NM 18:2012 }\end{array}$ & $\leq 12,5 \%$ & $\begin{array}{l}\text { Adotou-se o critério referente ao CP II-F, } \\
\text { por este apresentar teor de material } \\
\text { carbonático entre } 11 \% \text { e } 25 \% \text {, o que } \\
\text { abrange os cimentos estudados. }\end{array}$ \\
\hline & \multicolumn{2}{|c|}{$\begin{array}{l}\text { Teor de óxido de } \\
\text { magnésio }(\mathrm{MgO})\end{array}$} & $\begin{array}{l}\text { ABNT NBR } \\
\text { NM } 14: 2012\end{array}$ & - & $\begin{array}{l}\text { Esse critério não se aplica para cimentos } \\
\text { com adições minerais }\end{array}$ \\
\hline & \multicolumn{2}{|c|}{$\begin{array}{l}\text { Teor de trióxido de } \\
\text { enxofre }\left(\mathrm{SO}_{3}\right)\end{array}$} & $\begin{array}{l}\text { ABNT NBR } \\
\text { NM 16:2012 }\end{array}$ & $\leq 4,5 \%$ & $\begin{array}{l}\text { Critério aplicado a todos os cimentos da } \\
\text { ABNT NBR 16697:2018. }\end{array}$ \\
\hline \multirow{3}{*}{$\begin{array}{l}\text { Características } \\
\text { físicas }\end{array}$} & \multicolumn{2}{|c|}{ Finura } & $\begin{array}{l}\text { ABNT NBR } \\
11579: 2013 \\
\end{array}$ & $\leq 8,0 \%$ & $\begin{array}{l}\text { O critério adotado refere-se ao CP III e CP } \\
\text { IV e é inferior ao requerido para o CP II-F. }\end{array}$ \\
\hline & \multicolumn{2}{|c|}{ Tempo de pega } & $\begin{array}{l}\text { ABNT NBR } \\
16607: 2018 \\
\end{array}$ & $\geq 60 \mathrm{~min}$ & $\begin{array}{c}\text { Critério para todos os cimentos } \\
\text { normalizados. }\end{array}$ \\
\hline & \multicolumn{2}{|c|}{$\begin{array}{c}\text { Expansibilidade a } \\
\text { quente }\end{array}$} & $\begin{array}{l}\text { ABNT NBR } \\
11582: 2016 \\
\end{array}$ & $\leq 5 \mathrm{~mm}$ & $\begin{array}{c}\text { Critério para todos os cimentos } \\
\text { normalizados. }\end{array}$ \\
\hline \multirow{3}{*}{$\begin{array}{l}\text { Propriedade } \\
\text { mecânica }\end{array}$} & \multirow{3}{*}{$\begin{array}{l}\text { Resistência à } \\
\text { compressão } \\
\text { axial }\end{array}$} & 3 dias & \multirow{3}{*}{$\begin{array}{l}\text { ABNT NBR } \\
7215: 2019\end{array}$} & \multirow{3}{*}{\multicolumn{2}{|c|}{$\begin{array}{c}\text { Varia conforme a classe }(25,32,40) \text { e o tipo de } \\
\text { cimento } \\
\text { Detalhado na Tabela } 7\end{array}$}} \\
\hline & & 7 dias & & & \\
\hline & & 28 dias & & & \\
\hline
\end{tabular}




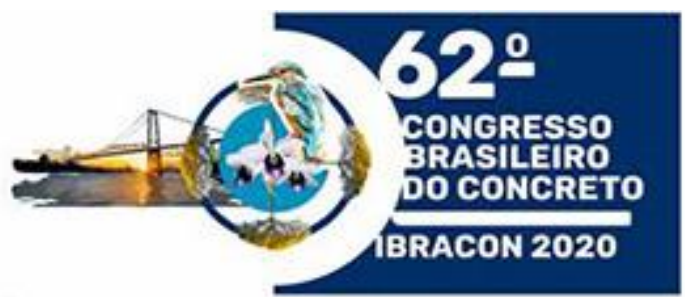

Anais do

$62^{\circ}$ Congresso Brasileiro do Concreto $\mathrm{CBC} 2020$

Setembro / 2020

(@) 2020 - IBRACON - ISSN 2175-8182

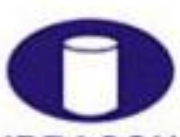

IBRACON

Tabela 7 - Critérios de resistência à compressão axial conforme a idade, classe e tipo de cimento descritos na ABNT NBR 16697:2108 (Fonte: ABNT NBR 16697:2018)

\begin{tabular}{|c|c|c|}
\hline \multirow{2}{*}{ Idade } & $\begin{array}{c}\text { Classe e tipo de } \\
\text { cimento }\end{array}$ & $\begin{array}{c}\text { Resistência à } \\
\text { compressão (MPa) }\end{array}$ \\
\hline \multirow{4}{*}{3 dias } & 25 & 8 \\
\cline { 2 - 3 } & 32 & 10 \\
\cline { 2 - 3 } & $40-$ CP III e CP IV & 12 \\
\cline { 2 - 3 } 7 dias & $40-$ CP II - F & 15 \\
\cline { 2 - 3 } & 25 & 15 \\
\cline { 2 - 3 } & $40-$ CP III e CP IV & 20 \\
\cline { 2 - 3 } & $40-$ CP II - F & 23 \\
\hline \multirow{4}{*}{28 dias } & 25 & 25 \\
\cline { 2 - 3 } & 32 & 25 \\
\cline { 2 - 3 } & 40 & 32 \\
\hline
\end{tabular}

\section{Apresentação e discussão dos resultados}

\subsection{Avaliação do desempenho ambiental}

A Figura 3 apresenta o resultado das emissões de GEE (em $\mathrm{CO}_{2 e q}$ ) para os cimentos estudados e a emissão máxima esperada (L.E.) por tonelada de cimento médio nacional em 2050, considerando as recomendações do Cement Technology Roadmap Brazil 2050 (SNIC, 2019), decorrentes apenas da contribuição das adições minerais. Todos os cimentos estudados atendem ao limite projetado para 2050.

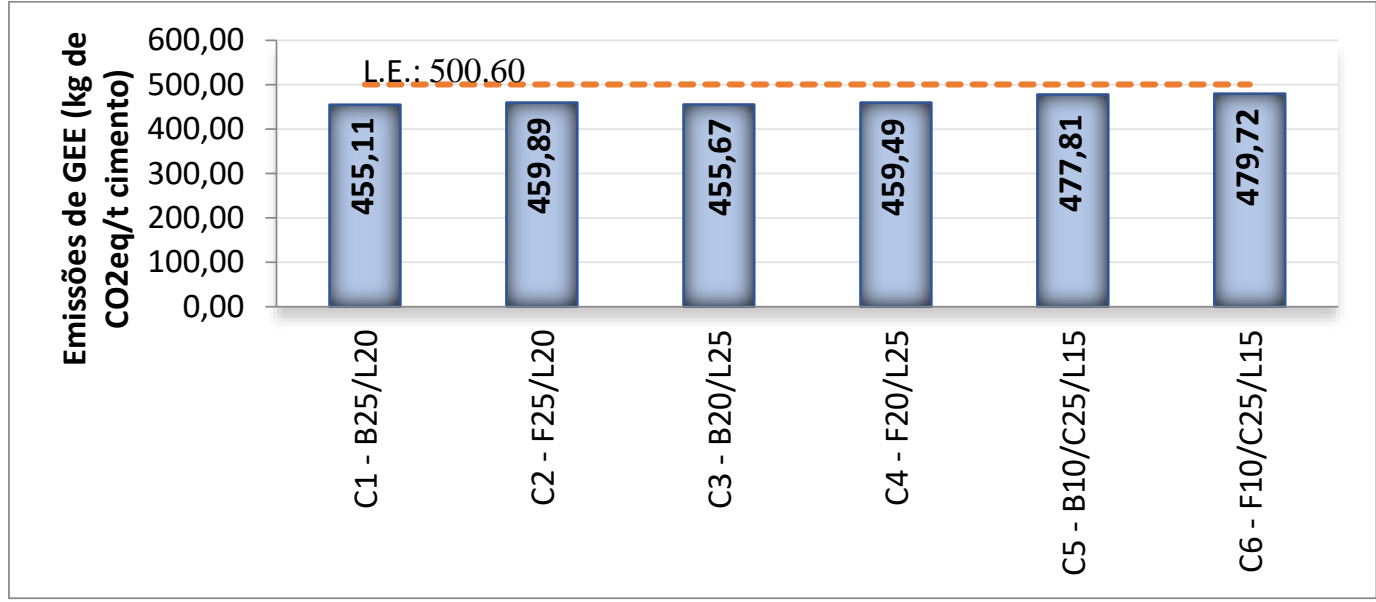

Figura 3 - Emissão de GEE dos cimentos estudados e a emissão máxima admitida para o cimento nacional (L.E.) em 2050, em $\mathrm{kgCO}_{2 \mathrm{eq}}$ / tonelada de cimento, considerando as recomendações do Cement Technology Roadmap Brazil 2050 (SNIC, 2019) apenas quanto a contribuição das adições minerais (Fonte: os autores)

\subsection{Avaliação do desempenho técnico}

\subsubsection{Características químicas}




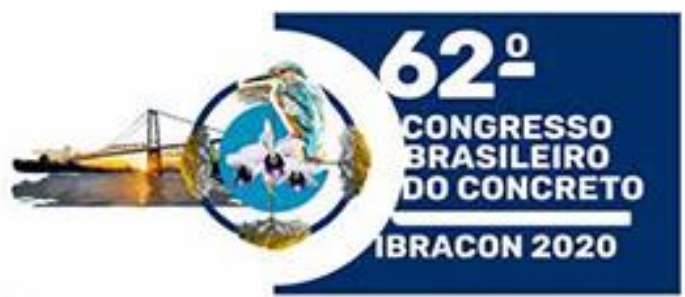

Anais do

$62^{\circ}$ Congresso Brasileiro do Concreto CBC2020

Setembro / 2020

(C) 2020 - IBRACON - ISSN 2175-8182

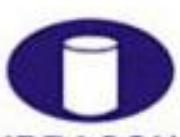

IBRACON

A Figura 4 mostra os valores obtidos para as características químicas dos cimentos estudados, quais sejam: resíduo insolúvel, perda ao fogo, óxido de magnésio e trióxido de enxofre.

Da Figura 4-a), observa-se que os cimentos C1 - B25/L20 e C3 - B20/L25 atenderam ao critério definido na ABNT NBR 16697:2018 para resíduo insolúvel. Para os demais cimentos, assim como no CP IV, o resíduo insolúvel não é um critério a ser avaliado. No entanto, os valores determinados foram elevados, devido à presença de materiais pozolânicos. Na última revisão da norma brasileira referente ao cimento Portland, ABNT NBR 16697:2018, percebe-se um aumento no critério de resíduo insolúvel para alguns cimentos, como o CP II-F, CP II-Z e CP III. Tal incremento é acompanhado do aumento do teor de fíler calcário e de outras adições minerais permitido em norma. Assim, ao buscar teores ainda mais elevados de substituição do clínquer por adições minerais, este requisito deveria ser avaliado e revisto.

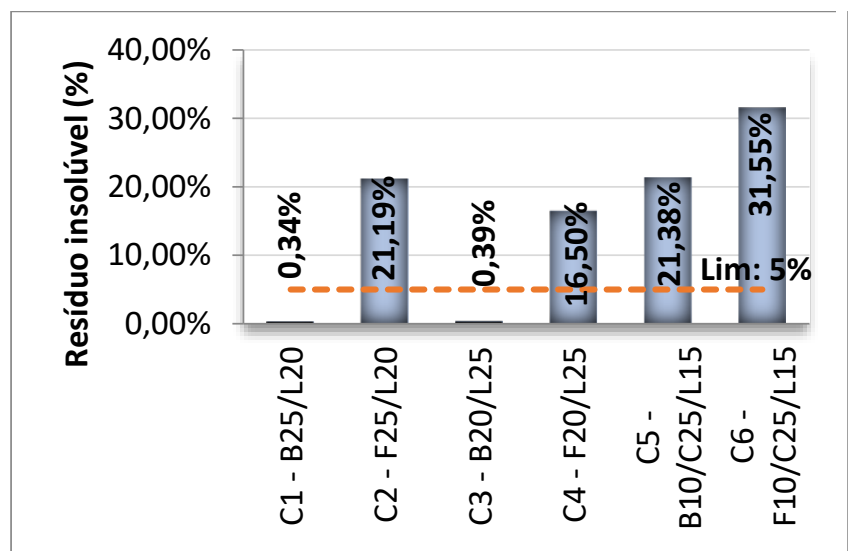

a)

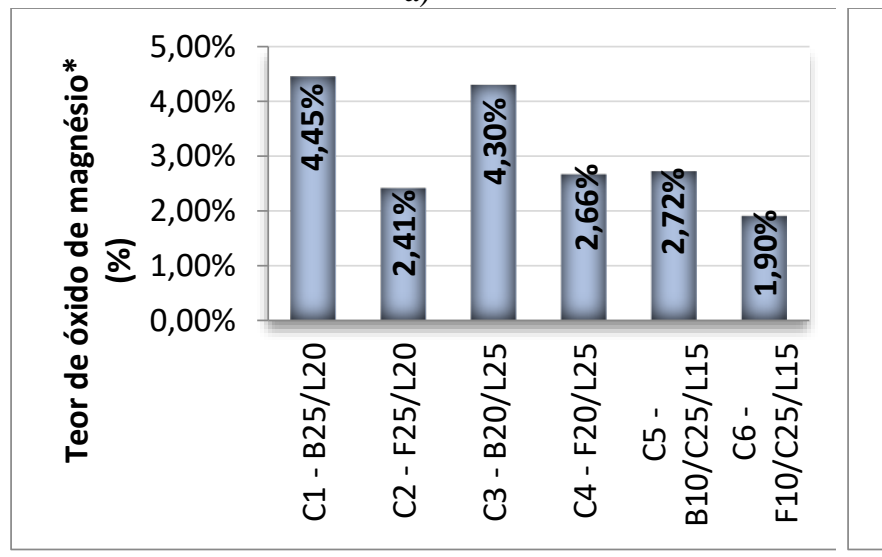

*não tem um valor limite

c)

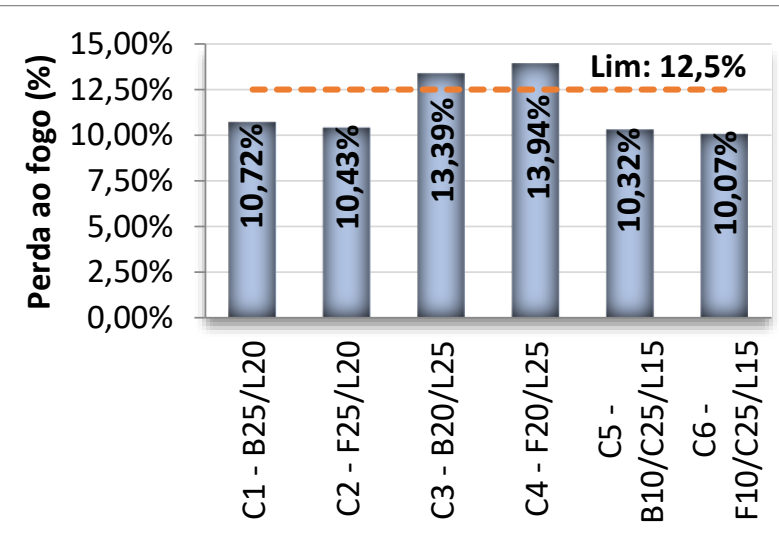

b)

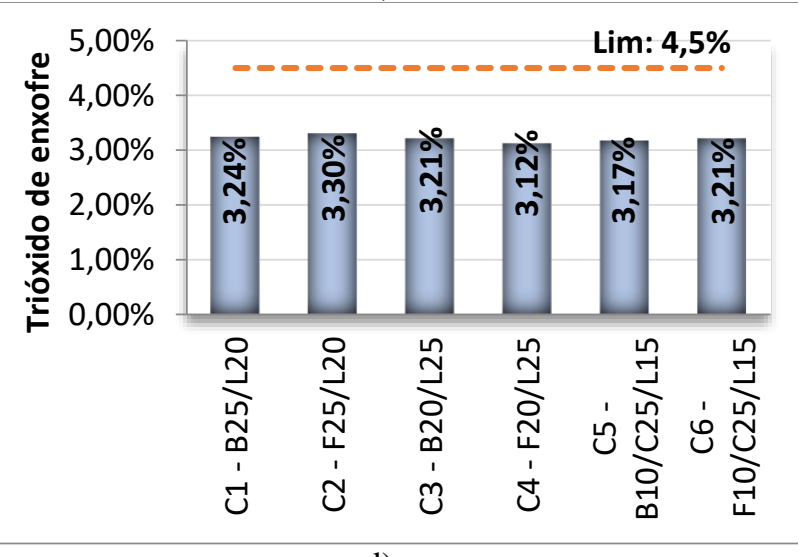

d)

Figura 4 - Resultados das características químicas dos cimentos estudados: resíduo insolúvel (a), perda ao fogo (b), óxido de magnésio (\%) e trióxido de enxofre (d) (Fonte: os autores)

Os cimentos C3 - B20/L25 e C4 - F20/L25 não atenderam ao critério referente a perda ao fogo (Figura 4-b). O elevado teor de fíler calcário desses cimentos (25\%) contribuiu para este resultado, pois a perda ao fogo do fíler calcário é elevada. O Cement Technology Roadmap Brazil 2050 (SNIC, 2019) prevê um aumento do teor de fíler calcário no cimento ANAIS DO 62 CONGRESSO BRASILEIRO DO CONCRETO - CBC2020 - 62CBC2020 


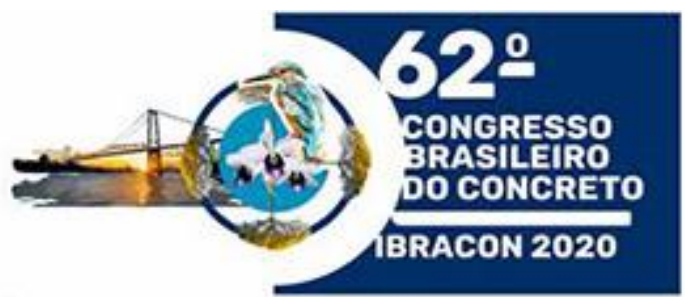

Anais do

$62^{\circ}$ Congresso Brasileiro do Concreto CBC2020

Setembro / 2020

(@) 2020 - IBRACON - ISSN 2175-8182

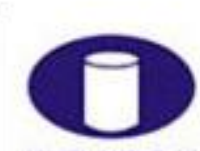

IBRACON

médio brasileiro, chegando a $25 \%$ em 2050. Assim, é necessário que a normalização brasileira seja adaptada para permitir o uso desses cimentos com elevados teores de fíler calcário.

Apesar de não haver critério para óxido de magnésio quando o cimento possui adições minerais, as adições minerais podem apresentar $\mathrm{MgO}$ e contribuir para o aumento desse teor no cimento. Como o óxido de magnésio proveniente de adições minerais como a escória de alto-forno não se encontra sob a forma de periclásio, não é prejudicial ao cimento (BATTAGIN, 2011). O projeto da norma europeia prEN 197-1:2019 limita o teor de MgO em $5 \%$ para o clínquer e não para o cimento, sendo esta uma sugestão para alteração da base normativa brasileira quanto ao teor de MgO. A Figura 4-c apresenta os teores de óxido de magnésio determinados para todos os cimentos.

Todos os cimentos estão dentro do limite referente ao trióxido de enxofre (Figura 4-d). O objetivo de se manter esse teor dentro do limite estabelecido em norma é evitar a formação de etringita em idades mais avançadas, ocasionando fissuração por expansão (TAYLOR et al., 2001).

\subsubsection{Características físicas}

A Figura 5 mostra os valores obtidos para as propriedades físicas exigidas na ABNT NBR 16697:2018, quais sejam: finura na peneira $75 \mu \mathrm{m}$, tempo de início de pega e expansibilidade a quente.

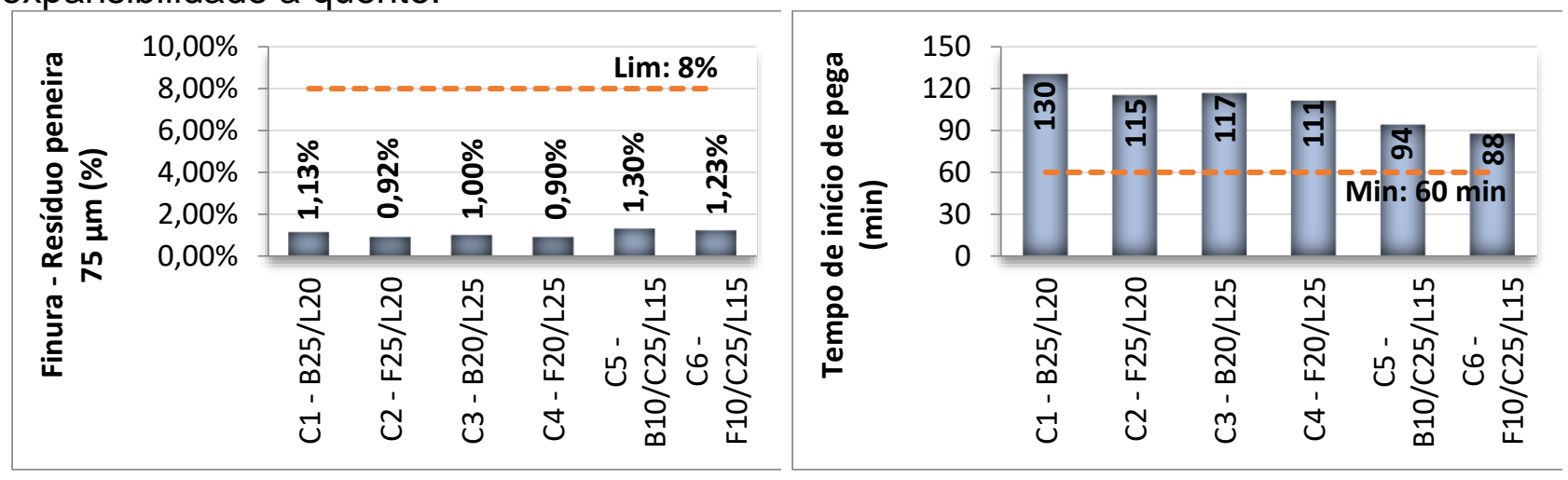

a)

b)

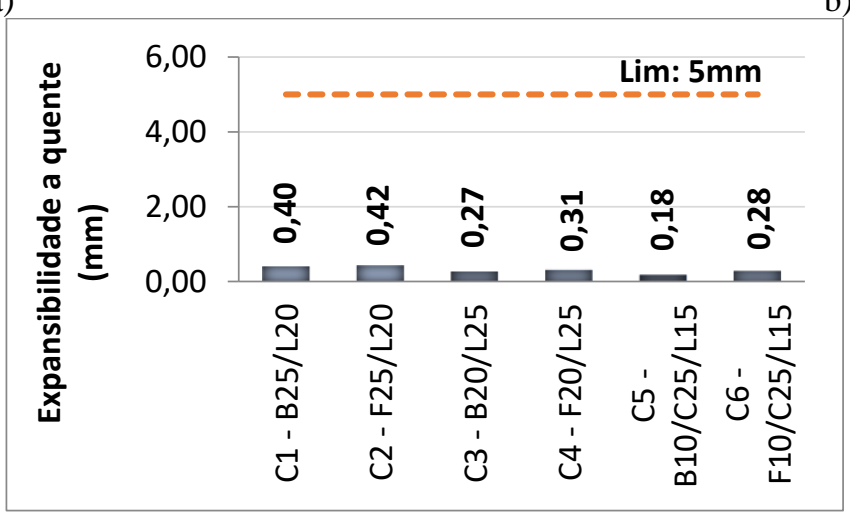

c)

Figura 5 - Resultado das características físicas: finura na peneira $75 \mu \mathrm{m}$ (a), tempo de início de pega (b), expansibilidade a quente (c) (Fonte: os autores)

Todos os cimentos estudados apresentaram menos do que $8 \%$ de material retido na peneira de malha $75 \mu \mathrm{m}\left(\mathrm{n}^{\circ} 200\right)$ (Figura 5-a) e tempo de início de pega superior a 60 ANAIS DO 62ํㅡㄴ CONGRESSO BRASILEIRO DO CONCRETO - CBC2020 - 62CBC2020 


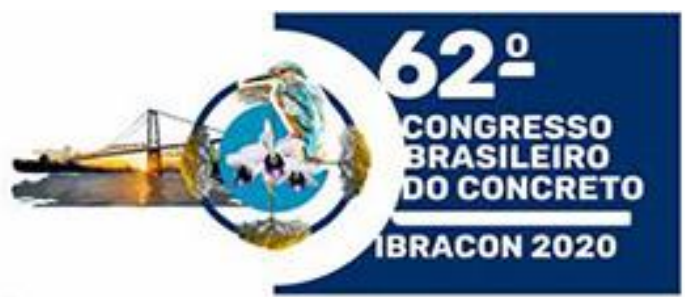

Anais do

$62^{\circ}$ Congresso Brasileiro do Concreto CBC2020

Setembro / 2020

(C) 2020 - IBRACON - ISSN 2175-8182

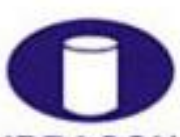

IBRACON

minutos (Figura 5-b), em conformidade com a ABNT NBR 16697:2018. Observa-se que, ao elevar o teor de fíler calcário de 20 para $25 \%$, não houve grandes alterações no tempo de início de pega dos cimentos. Tampouco se observa grandes variações quanto ao tempo de pega dentre os cimentos compostos por escória de alto-forno ou cinza volante. No entanto, nota-se redução no tempo de início de pega dos cimentos contendo argila calcinada.

A Figura 5-c) mostra que todos os cimentos também atendem à ABNT NBR16697:2018 quanto à expansibilidade a quente dos cimentos estudados.

\subsubsection{Propriedade mecânica}

A Figura 6 apresenta os resultados médios de resistência à compressão dos cimentos estudados aos 3, 7 e 28 dias de idade. A Tabela 8, posiciona os cimentos estudados em relação aos cimentos normalizados no Brasil, considerando os critérios conforme as classes e alguns tipos de cimentos da ABNT NBR 16697:2018.

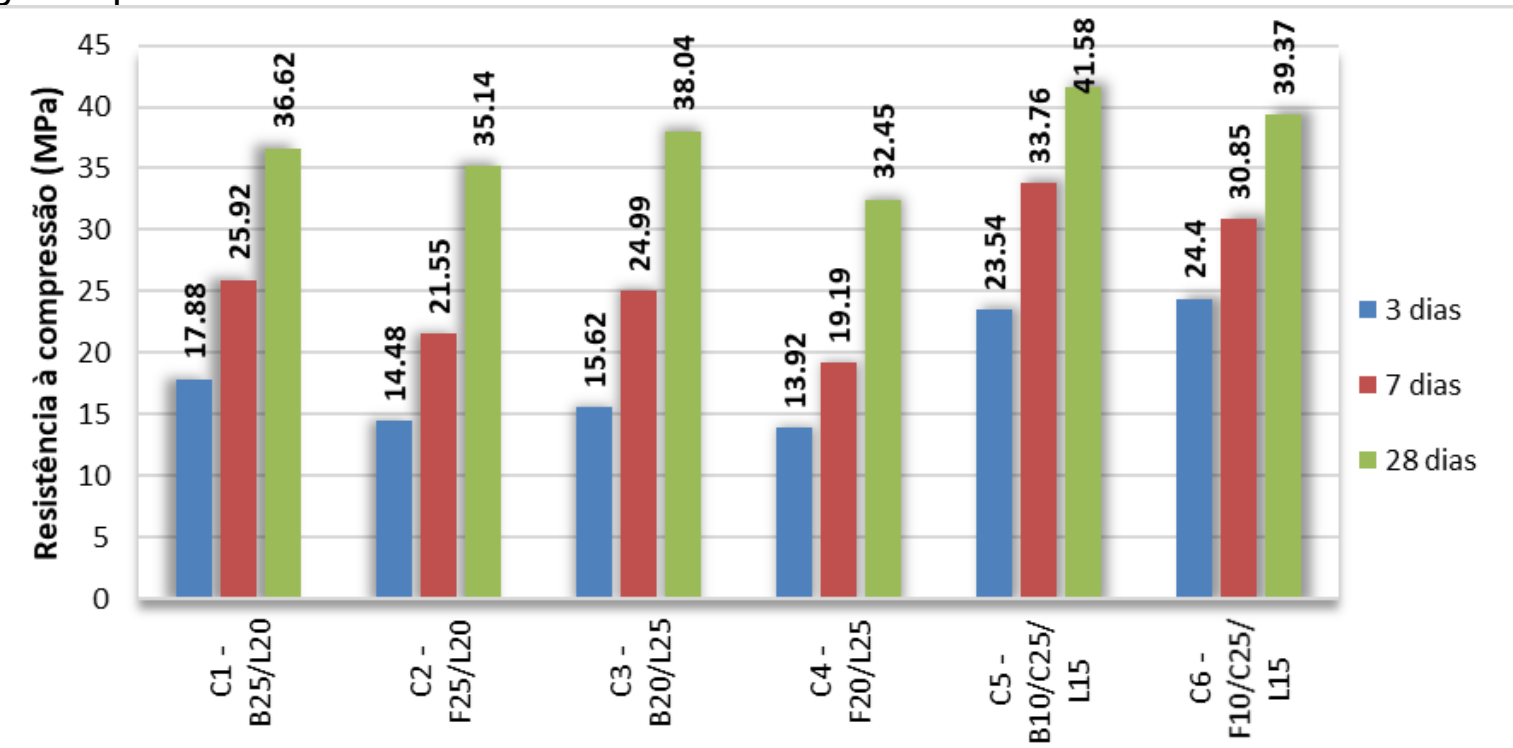

Figura 6 - Resultados da resistência à compressão dos cimentos estudados nas idades de 3, 7 e 28 dias (Fonte: os autores)

Todos os cimentos estudados atenderam ao menos ao critério de uma das classes de cimentos normalizados no Brasil (Figura 6, Tabela 8). No entanto, observa-se que somente o C5 - B10/C25/L15 (45\% clínquer | 10\% escória de alto-forno | 25\% argila calcinada | 15\% fíler calcário) atingiu a resistência de $40 \mathrm{MPa}$ aos 28 dias. Isso demostra que estudos relacionados ao efeito sinérgico entre as adições minerais, especialmente as composições com fíler calcário, devem ser realizados a fim de atingir melhores resistências mecânicas. 


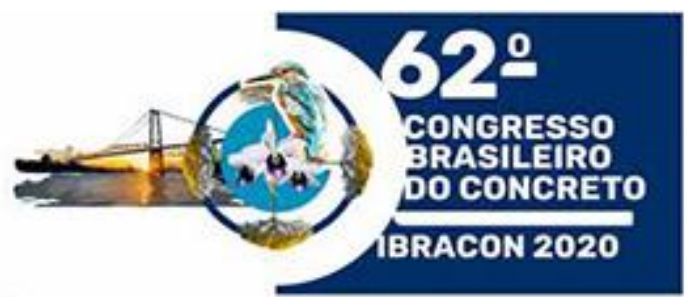

Anais do

$62^{\circ}$ Congresso Brasileiro do Concreto CBC2020

Setembro / 2020

(@) 2020 - IBRACON - ISSN 2175-8182

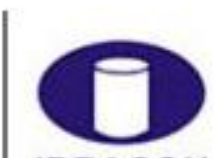

IBRACON

Tabela 8 - Resistência a compressão dos cimentos estudados em relação à dos cimentos brasileiros normalizados (Fonte: aos autores)

\begin{tabular}{|c|c|c|c|c|c|c|c|c|}
\hline Idade & $\begin{array}{l}\text { Classe e } \\
\text { tipo de } \\
\text { cimento } \\
\end{array}$ & $\begin{array}{c}\text { Resistência à } \\
\text { compressão } \\
(\mathrm{MPa})\end{array}$ & $\begin{array}{c}\mathrm{C} 1- \\
\text { B25/L20 }\end{array}$ & $\begin{array}{c}\mathrm{C} 2- \\
\text { F25/L20 }\end{array}$ & $\begin{array}{c}\text { C3 - } \\
\text { B20/L25 }\end{array}$ & $\begin{array}{c}\text { C4 - } \\
\text { F20/L25 }\end{array}$ & $\begin{array}{c}\text { C5 - } \\
\text { B10/C25/L15 }\end{array}$ & $\begin{array}{c}\text { C6 - } \\
\text { F10/C25/L15 }\end{array}$ \\
\hline \multirow{4}{*}{$\begin{array}{c}3 \\
\text { dias }\end{array}$} & 25 & 8 & $\checkmark$ & $\checkmark$ & $\checkmark$ & $\checkmark$ & $\checkmark$ & $\checkmark$ \\
\hline & 32 & 10 & $\checkmark$ & $\checkmark$ & $\checkmark$ & $\checkmark$ & $\checkmark$ & $\checkmark$ \\
\hline & $\begin{array}{c}40-\text { CP III } \\
\text { e CP IV }\end{array}$ & 12 & $\checkmark$ & $\checkmark$ & $\checkmark$ & $\checkmark$ & $\checkmark$ & $\checkmark$ \\
\hline & $\begin{array}{c}40-\text { CP II } \\
- \text { F }\end{array}$ & 15 & $\checkmark$ & $x$ & $\checkmark$ & $x$ & $\checkmark$ & $\checkmark$ \\
\hline \multirow{4}{*}{$\begin{array}{c}7 \\
\text { dias }\end{array}$} & 25 & 15 & $\checkmark$ & $\checkmark$ & $\checkmark$ & $\checkmark$ & $\checkmark$ & $\checkmark$ \\
\hline & 32 & 20 & $\checkmark$ & $\checkmark$ & $\checkmark$ & $x$ & $\checkmark$ & $\checkmark$ \\
\hline & $\begin{array}{c}40-\text { CP III } \\
\text { e CP IV }\end{array}$ & 23 & $\checkmark$ & $x$ & $\checkmark$ & $x$ & $\checkmark$ & $\checkmark$ \\
\hline & $\begin{array}{c}40-\text { CP II } \\
- \text { F }\end{array}$ & 25 & $\checkmark$ & $x$ & $x$ & $x$ & $\checkmark$ & $\checkmark$ \\
\hline \multirow{3}{*}{$\begin{array}{c}28 \\
\text { dias }\end{array}$} & 25 & 25 & $\checkmark$ & $\checkmark$ & $\checkmark$ & $\checkmark$ & $\checkmark$ & $\checkmark$ \\
\hline & 32 & 32 & $\checkmark$ & $\checkmark$ & $\checkmark$ & $\checkmark$ & $\checkmark$ & $\checkmark$ \\
\hline & 40 & 40 & $x$ & $x$ & $x$ & $x$ & $\checkmark$ & $x$ \\
\hline
\end{tabular}

\section{Conclusões}

Alinhado à tendência mundial, o Brasil está dando importantes passos para a redução das emissões de GEE (em $\mathrm{CO}_{2 e q}$ ) oriunda da indústria de cimento. A elaboração do Cement Technology Roadmap Brazil 2050, assim como as revisões das normas brasileiras de cimento, são exemplos de avanços no cenário nacional.

Dentre as alternativas que apresentam o maior potencial para a redução das emissões de GEE (em $\mathrm{CO}_{2 e q}$ ), está o uso de adições minerais combinadas, que possibilitam reduzir o fator de clínquer para próximo de $50 \%$. Isso se deve a ocorrência de um efeito sinérgico entre as adições minerais, que pode melhorar as propriedades dos cimentos e dos concretos.

No Brasil, a ABNT NBR 16697:2018 determina requisitos obrigatórios que os cimentos normalizados devem atender. Os resultados dessa investigação evidenciaram a viabilidade de cimentos com elevado teor de adições minerais combinadas, por atenderem às exigências quanto ao resíduo insolúvel $(\mathrm{RI})$, teor de óxido de magnésio ( $\mathrm{MgO})$, teor de trióxido de enxofre $\left(\mathrm{SO}_{3}\right)$, finura, tempo de início de pega e expansibilidade, além de pelo menos uma das classes de resistência à compressão. Em relação a resistência mecânica, o cimento C5 - B10/C25/L15 merece destaque por atingir $40 \mathrm{MPa}$ aos 28 dias, característica desejável na construção civil. No entanto, cimentos com elevados teores de fíler calcário especialmente aqueles que apresentam 25\%, como o C4 - F20/L25 - requerem atenção, pois, não atenderam à exigência de perda ao fogo, nem atingiram resistência à compressão para a classe 40.

O Cement Technology Roadmap Brazil 2050 projeta um teor de $25 \%$ de fíler calcário na composição média do cimento brasileiro em 2050. Isso significa que deve haver cimentos com menos de $25 \%$ de fíler calcário, como os atuais CP V (com até $10 \%$ ) e cimentos com mais de $25 \%$ de fíler calcário , como por exemplo, os da norma européia que admite até $35 \%$. Para a introdução desse último tipo de cimento no mercado e de cimentos com ANAIS DO 62 CONGRESSO BRASILEIRO DO CONCRETO - CBC2020 - 62CBC2020 


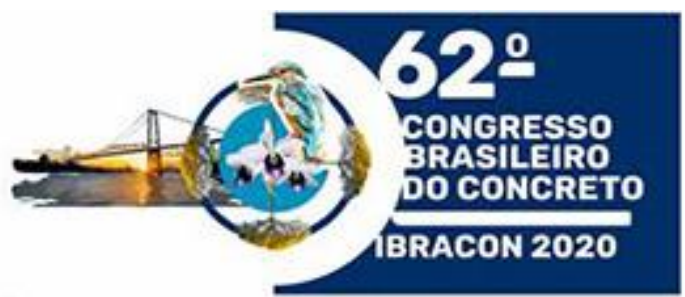

USO E OPERACAOA DE ESTRUTURAS DE CONCRETO
Anais do

$62^{\circ}$ Congresso Brasileiro do Concreto

CBC2020

Setembro / 2020

(C) 2020 - IBRACON - ISSN 2175-8182

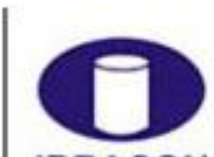

IBRACON

elevados teores de adições minerais combinadas, há necessidade de entender e melhorar a sinergia do fíler calcário com as demais adições minerais, a fim de viabilizar a elevação do teor de fíler calcário, sem afetar o desempenho técnico desses cimentos. Dentre as adições minerais a utilização conjuntamente com argila calcinadas tem despertado os pesquisadores internacionais.

Nas previsões e modelagem do Cement Technology Roadmap Brazil 2050, há um cenário de escassez de algumas adições minerais. Com isso, tornam-se indispensáveis o avanço e incentivo às pesquisas para desenvolver novas adições minerais e combinações de adições minerais que reduzam os impactos ambientais da cadeia produtiva do cimento, enquanto se garante o atendimento a exigências técnicas e mercadológicas.

\section{$5 \quad$ Agradecimentos}

Os autores agradecem a Coordenação de Aperfeiçoamento de Pessoal de Nível Superior - Brasil (CAPES) e ao Conselho Nacional de Desenvolvimento Científico e Tecnológico (CNPq) pelo apoio financeiro - bolsas DS e processo CNPq \#306048/2018-3; e ao Laboratório de Ensaios em Materiais de Construção da Universidade Federal do Espírito Santo e a Associação Brasileira de Cimento Portland pela disponibilidade na realização dos ensaios.

\section{Referências}

ADU-AMANKWAH, S.; ZAJAC, M.; STABLER, C.; LOTHENBACH, B.; BLACK, L. Influence of limestone on the hydration of ternary slag cements. Cement and Concrete Research, v. 100, p. 96-109, 2017.

ARORA, A.; SANT, G.; NEITHALATH, N. Ternary blends containing slag and interground/blended limestone: Hydration, strength, and pore structure. Construction and Building Materials, v. 102, p. 113-124, 2016.

ARVANITI, E. C.; JUENGER, M. C. G.; BERNAL, S. A.; DUCHESNE, J.; COURARD, L.; LEROY, S.; PROVIS, J. L.; KLEMM, A.; DE BELIE, N. Physical characterization methods for supplementary cementitious materials. Materials and Structures, v. 48, p. 3675-3686, 2015.

ASSOCIAÇÃO BRASILEIRA DE NORMAS TÉCNICAS. NBR 16697: Cimento Portland Requisitos. Rio de Janeiro: ABNT, 2018.

.NBR 15.895: Materiais pozolânicos - Determinação do teor de hidróxido de cálcio fixado - Método de Chapelle modificado. Rio de Janeiro: ABNT, 2010.

. NBR 11.579: Cimento Portland - Determinação do índice de finura por meio da peneira $75 \mu \mathrm{m}\left(\mathrm{n}^{\circ}\right.$ 200). Rio de Janeiro. ABNT, 2013.

NBR 16.607: Cimento Portland - Determinação dos tempos de pega. Rio de Janeiro. ABNT, 2018. 


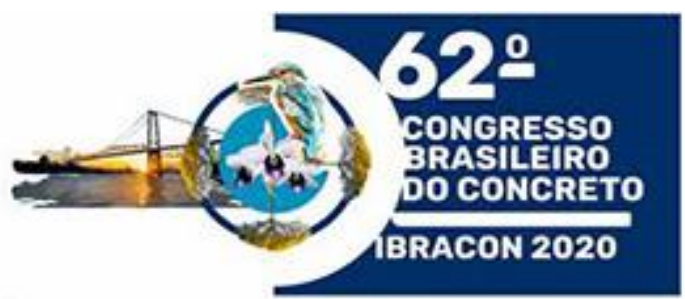

Anais do

$62^{\circ}$ Congresso Brasileiro do Concreto CBC2020

Setembro / 2020

(C) 2020 - IBRACON - ISSN 2175-8182

NBR NM 14: Cimento Portland - Análise química -Método de arbitragem para determinação de dióxido de silício, óxido férrico, óxido de alumínio, óxido de cálcio e óxido de magnésio. Rio de Janeiro. ABNT, 2012.

NBR NM 15: Cimento Portland - Análise química - Determinação de resíduo insolúvel. Rio de Janeiro. ABNT, 2012.

NBR NM 16: Cimento Portland - Análise química - Determinação de anidrido sulfúrico. Rio de Janeiro. ABNT, 2012.

NBR NM 18: Cimento Portland - Análise química - Determinação de perda ao fogo. Rio de Janeiro. ABNT, 2012.

.NBR 7.215: Cimento Portland - Determinação da resistência à compressão de corpos de prova cilíndricos. Rio de Janeiro: ABNT, 2019.

BATTAGIN, A. F. Cimento Portland. In: ISAIA, G. C. (Ed.). Concreto: Ciência e Tecnologia. v. 1, São Paulo, SP: IBRACON, p. 185-232, 2011.

FERNÁNDEZ, A.; GARCÍA CALVO, J. L.; ALONSO, M. C. Ordinary Portland Cement composition for the optimization of the synergies of supplementary cementitious materials of ternary binders in hydration processes. Cement and Concrete Composites, v. 89, p. 238-250, 2018.

GAO, Y.; DE SCHUTTER, G.; YE, G.; YU, Z. TAN, Z.; WU, K. A microscopic study on ternary blended cement based composites. Construction and Building Materials, v. 46, p. 28-38, 2013.

INTERGOVERNMENTAL PANEL ON CLIMATE CHANGE (IPCC). Climate Change 2013: The Physical Science Basis. Contribution of Working Group I to the Fifth Assessment Report of the Intergovernmental Panel on Climate Change [STOCKER, T. F.; QIN, D.; PLATTNER, G.-K.; TIGNOR, M. M. B.; Allen, S. K.; BOSCHUNG, J.; NAUELS, A.; XIA, Y.; BEX; V. and MIDGLEY, P. M. (eds)], Cambridge University Press, Cambridge, United Kingdom and New York, NY, USA, 2013. 1535p.

INTERNATIONAL ENERGY AGENCY (IEA). Evaluation of Embodied Energy and $\mathrm{CO}_{2 \text { eq }}$ for Building Construction (Annex 57): Overview of Annex 57 results. Disponível em http://www.iea-ebc.org/Data/publications/EBC Annex 57 Results Overview.pdf. 2016. 90p.

INTERNATIONAL ENERGY AGENCY (IEA). Assessing Life Cycle Related Environmental Impacts Caused by Buildings (Annex 72). Factsheet. Disponível em http://annex72.iea-ebc.org/Data/publications/EBC Annex 72 Factsheet.pdf. 2018. 


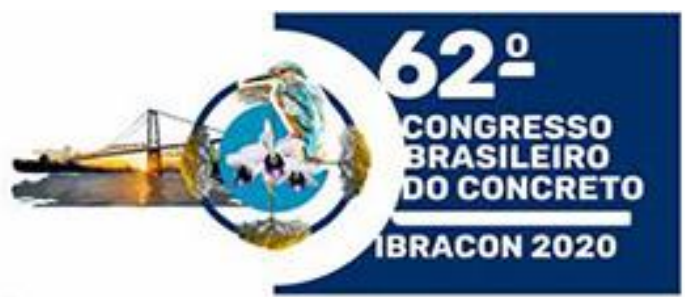

USO E OPERACAO DE ESTRUTURAS DE CONCRETO
Anais do

$62^{\circ}$ Congresso Brasileiro do Concreto $\mathrm{CBC} 2020$

Setembro / 2020

(C) 2020 - IBRACON - ISSN 2175-8182

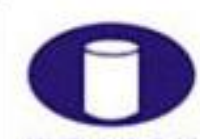

IBRACON

KRISHNAN, S.; EMMANUEL, A. C.; BISHNOI, S. Hydration and phase assemblage of ternary cements with calcined clay and limestone. Construction and Building Materials, v. 222, p. 64-72, 2019.

MENDES, A. A. F.; PAGIO, M. Z.; BATTAGIN, A. F.; SAADE, M. R. M.; GOMES, V.; SILVA, M. G. A contribuição das adições minerais para redução das emissões de gases de efeito estufa da indústria de cimento brasileira em 2050. In: 61 Congresso Brasileiro do Concreto. Fortaleza, IBRACON, 2019.

PUERTA-FALLA, G.; BALONIS, M.; LE SAOUT, G.; FALZONE, G.; ZHANG, C.; NEITHALATH, N.; SANT, G. Elucidating the Role of the Aluminous Source on Limestone Reactivity in Cementitious Materials. Journal of the American Ceramic Society, v. 98, p. 4076-4089, 2015.

RAVERDY M., BRIVOT F., PAILLERE A.M., DRON, R. "Appreciation de l'activite pouzzolanique des constituants secondaires", In: 7th Int. Congr. Chem. Cem. Paris, 1980.

ROADMAP TECNOLÓGICO DO CIMENTO: Potencial de redução das emissões de carbono da indústria do cimento brasileira até 2050. SNIC, ABCP, 2019.

SCRIVENER, K.; MARTINERA, F.; BISHNOI S.; MAITY, S.; Calcined clay limestone cements $\left(\mathrm{LC}^{3}\right)$. Cement and Concret Research, v. 114, p. 49-56, 2018b.

SILVA, M. G; BATTAGIN, A. F.; GOMES, V. Cimentos Portland com adições minerais. In: ISAIA, G. C. Materiais de Construção Civil e princípios de ciência e engenharia de materiais. $3^{\circ}$ edição. São Paulo: Ibracon, 2017. Cap. 25, p. 791-823.

SKIBSTED, J., SNELLINGS, R., Reactivity of supplementary cementitious materials (SCMs) in cement blends, Cement and Concrete Research, v. 124, 2019.

TAYLOR, H. F. W., FAMY, C., SCRIVENER, K. L. Delayed ettringite formation. Cement and Concrete Research, v.31, p.683-693, 2001.

VANCE, K. et. al. Hydration and strength development in ternary portland cement blends containing limestone and fly ash or metakaolin. Cement and Concrete Research, v. 39, p. 93-103, 2013.

WANG, D.; SHI, C.; FARZADNIA, N.; SHI, Z.; JIA, H.; OU, Z. A review on use of limestone powder in cement-based materials: Mechanism, hydration and microstructures. Construction and Building Materials, v. 181, p. 659-672, 2018.

WORLD BUSINESS COUNCIL FOR SUSTAINABLE DEVELOPMENT (WBCSD). Technology Roadmap. Low-Carbon Transition in the Cement Industry. 2018. <http://www.iea.org/publications/freepublications/publication/TechnologRoadmapLowCarb onTransitionintheCementIndustry.pdf> Acesso em 10 nov.19. 